\title{
Qualidade higiênica de leite caprino por contagem de coliformes e estafilococos
}

\author{
Goat's milk quality by coliform's and staphylococci counting
}

\author{
Carina Philomena Tebisch Gottardi ${ }^{\mathrm{I}}$ Renata Fernandes Muricy \\ Marisa Cardoso ${ }^{I}$ Verônica Schmidt ${ }^{*}$
}

\section{RESUMO}

O objetivo deste estudo foi investigar os padrões higiênicos do leite de mistura caprino produzido por oito propriedades associadas a uma cooperativa na região do Vale do Taquari - RS. Foram realizadas duas visitas às propriedades durante o período de maior produção leiteira. As propriedades foram avaliadas quanto às instalações, ao manejo de ordenha $e$ ao armazenamento do leite.Foram coletadas amostras de leite e água em cada visita. As amostras de água apresentaram contagem de coliformes dentro dos limites propostos pela legislação vigente, já as de leite apresentaram contagens de coliformes totais que variaram de zero a $1,4 \times 10^{6} \mathrm{UFC} \mathrm{mL}^{-1}$. Em apenas duas propriedades foram encontrados coliformes fecais. Não foram identificados estafilococos coagulase-positiva nas amostras. Não foi evidenciada relação significativa entre os sistemas de resfriamento e ordenha empregados na propriedade e a presença de coliformes no leite.

Palavras-chave: leite de rebanho, leite de cabra, Escherichia coli, estafilococos coagulase-negativa.

\section{ABSTRACT}

The aim of this work was to evaluate the current hygiene-sanitary quality of milk produced by eight dairy goat farms located in Vale do Taquari region, state of Rio Grande do Sul, Brazil. On each farm, two samplings were performed during the highest milk yield period. At each sampling, bulk milk and water samples were taken, and farms were checked for their facilities, milking management and milk storage. Water samples were subjected to fecal coliform enumeration, while milk samples were tested for total and fecal colifoms as well as for coagulase-positive staphylococci. Water samples presented fecal coliform levels according to the national legislation. In milk samples total coliform counts up to $1.4 \times 10^{6} \mathrm{CFU} \mathrm{mL}^{-1}$ were found. Coagulase-positive staphylococci were not isolated and fecal coliforms were detected in two farms. No correlation was observed between the number of total coliforms and milking management and milk storage.
Key words: bulk tank milk, goat milk, Escherichia coli, coagulase-negative staphylococci.

\section{INTRODUÇÃO}

As condições higiênico-sanitárias em que ocorre a ordenha e o armazenamento do leite, nas propriedades que exploram a caprinocultura leiteira, são ainda pouco conhecidas no Sul do Brasil. Condições higiênicas inadequadas durante a obtenção do leite poderão resultar em mastite e, conseqüentemente, em perda de sua qualidade, levando a prejuízos financeiros pela possível rejeição do produto. Entre essas perdas, destaca-se a acidificação decorrente da multiplicação bacteriana no leite, que pode ocorrer durante o período que compreende $\mathrm{o}$ armazenamento na propriedade e $\mathrm{o}$ transporte até a indústria.

Entre os indicadores comumente utilizados da qualidade higiênico-sanitária dos alimentos, encontram-se as contagens de coliformes e de estafilococos coagulase-positiva. Os coliformes são indicadores de contaminação fecal e do risco da presença de microorganismos patogênicos, que podem causar toxinfecções no consumidor. Os estafilococos são de grande importância, principalmente os coagulase-positiva, pois podem produzir enterotoxinas termoestáveis, que podem chegar ao consumidor mesmo após pasteurização (CARDOSO et al., 1985).

Em estudo realizado anteriormente em um laticínio que industrializa leite caprino na Grande Porto Alegre, RS, observou-se rejeição na plataforma, por

IDepartamento de Medicina Veterinária Preventiva, Faculdade de Veterinária (FAVET), Universidade Federal do Rio Grande do Sul (UFRGS). Av. Bento Gonçalves, 9090, 91509-900, Porto Alegre, RS, Brasil. E-mail: veronica.schmidt@ufrgs.br. *Autor para correspondência. 
acidez, de grande parte do leite recebido de pequenas propriedades pertencentes a uma cooperativa de produtores (PICOLI et al., 2006). A acidez do leite pode aumentar através da hidrólise da lactose por enzimas microbianas, que leva à formação de ácido lático. Dessa forma, acidez elevada indica alta atividade microbiana, a qual, por sua vez, pode ser dependente do estado de conservação das amostras (PRATA et al., 1998) ou dos procedimentos de higiene, durante o processo de obtenção do leite.

Dessa forma, o objetivo do presente trabalho foi verificar associações entre as condições de ordenha e armazenamento do leite e as características higiênico-sanitárias do leite caprino produzido em propriedades com histórico de rejeição de leite por acidez na plataforma de recepção do laticínio.

\section{MATERIAL E MÉTODOS}

Na tomada de amostras para este trabalho, utilizaram-se critérios qualitativos, recorrendo-se à chamada amostra intencional (THIOLLENT, 1992; MARCONI \& LAKATUS, 1996). Foram realizadas duas visitas, com intervalo de 30 dias, a oito propriedades produtoras de leite de cabra associadas a uma cooperativa de produtores, no vale do Taquari/RS. A Cooperativa constitui-se de pequenas propriedades com atividades diversificadas do setor agropecuário. Entre as propriedades associadas, 13 possuem estrutura para produção de leite de cabra, sendo que oito já haviam implementado esta atividade, constituindo-se, assim, na totalidade de propriedades avaliadas no presente trabalho (identificadas seqüencialmente de 1 a 8). Na primeira visita, as propriedades foram avaliadas quanto ao tipo de instalações, à rotina de ordenha e à forma de armazenamento do leite. Quanto à plataforma de ordenha, observou-se a localização (contígua ou separada do galpão), o material utilizado na construção (madeira ou alvenaria revestida com azulejos), a presença ou não de canzil e a prática do arraçoamento durante a ordenha.

As amostras de leite de mistura foram coletadas no resfriador com o auxílio de pipetas esterilizadas, sendo acondicionadas em frascos esterilizados e transportadas, sob refrigeração, ao laboratório, onde as amostras foram diluídas até $10^{-5}$ em água peptonada a $0,1 \%$. Alíquotas de $1 \mathrm{~mL}$ de cada diluição foram utilizadas para a contagem de coliformes totais em ágar Vermelho Violeta Bile (VRB), conforme SILVA et al. (1997). A confirmação de coliformes termotolerantes foi feita semeando-se cinco colônias típicas em caldo EC, incubado $\left(44,5^{\circ} \mathrm{C} / 48 \mathrm{~h}\right)$ em banhomaria sob agitação (68rpm min $\left.{ }^{-1}\right)$, sendo considerados positivos aqueles em que houve formação de gás.

Das mesmas diluições, foram semeadas alíquotas de 0,1mL na superfície de ágar Baird Parker para a contagem de estafilococos (SILVA et al., 1997). Após incubação $\left(37^{\circ} \mathrm{C} / 24-48 \mathrm{~h}\right)$, contaram-se unidades formadoras de colônias consideradas típicas (negras com halo translúcido) e atípicas, sendo que pelo menos cinco colônias foram submetidas à confirmação pelo teste de coagulase em tubo.

Concomitantemente às coletas de leite, amostrou-se a água utilizada na higienização de úberes e utensílios na propriedade, que foi analisada quanto à determinação do Número Mais Provável (NMP) de coliformes totais e fecais, segundo FRANSON (1995).

A análise estatística foi realizada pelo teste Kruskal-Wallis para a comparação das médias de coliformes e estafilococos em propriedades que utilizam ordenha mecânica ou manual e armazenamento do leite em tanque de expansão ou latões em imersão. A associação entre presença de coliformes no leite e na água das propriedades foi realizada pelo teste exato de Fisher. Utilizou-se o programa InStat versão 2.0, aplicando-se um nível de significância de $5 \%(\alpha=0,05)$ (PAGANO \& GAUVREAU, 2000).

\section{RESULTADOS E DISCUSSÃO}

O número de caprinos que compunham o rebanho das propriedades variou entre 27 e 202 animais, independentemente de idade e sexo (Tabela 1), encontrando-se, no máximo, 50 animais em lactação.

Nas propriedades estudadas, predominaram $(87,5 \%)$ plataformas de ordenha onde os animais ficavam dispostos lado a lado, estando o ordenhador posicionado atrás do animal. Este modelo de plataforma permite que os animais recebam concentrados como suplementação alimentar durante a ordenha (LE DU, 1987). No período de lactação, um caprino pode ingerir de 340 a 454g de concentrado, possibilitando controle maior sobre a quantidade de ração ingerida e a produção de leite (MACKENZIE, 1980). Por outro lado, esta prática de manejo pode predispor à contaminação do leite, especialmente na ordenha manual, adotada em três propriedades.

Embora a ordenha manual ocupe o ordenhador por 6 a 7 minutos/cabra e, na ordenha mecânica, este tempo seja reduzido para 4 minutos/ animal (MACKENZIE, 1980), a ordenha e os procedimentos relacionados a ela podem representar 
Tabela 1 - Características de oito propriedades produtoras de leite caprino, pertencentes a uma Cooperativa de produtores no Vale do Taquari, Rio Grande do Sul.

\begin{tabular}{|c|c|c|c|c|c|c|c|c|}
\hline \multicolumn{9}{|c|}{ Propriedades } \\
\hline & 1 & 2 & 3 & 4 & 5 & 6 & 7 & 8 \\
\hline Rebanho $^{1}$ & 83 & 112 & 37 & 202 & 144 & 73 & 48 & 27 \\
\hline Ordenha $^{2}$ & $\mathrm{Me}$ & Me & $\mathrm{Ma}$ & $\mathrm{Me}$ & $\mathrm{Me}$ & $\mathrm{Me}$ & $\mathrm{Ma}$ & Ma \\
\hline Plataforma $^{3}$ & $\mathrm{M} / \mathrm{C}$ & $\mathrm{M} / \mathrm{C}$ & $\mathrm{M} / \mathrm{C}$ & $\mathrm{M} / \mathrm{C}$ & $\mathrm{M} / \mathrm{C}$ & $\mathrm{A} / \mathrm{C} / \mathrm{Sg}$ & $\mathrm{M} / \mathrm{C} / \mathrm{Sg}$ & $\mathrm{M} / \mathrm{C}$ \\
\hline Arraçoamento ${ }^{4}$ & $\mathrm{C}$ & $\mathrm{S}$ & $\mathrm{C}$ & $\mathrm{C}$ & $\mathrm{C}$ & $\mathrm{S}$ & $\mathrm{S}$ & $\mathrm{C}$ \\
\hline Produção (L/dia) & 50 & 20 & 20 & 100 & 32 & 41,4 & 20 & 12 \\
\hline Resfriamento $^{5}$ & I & I & I & $\mathrm{T}$ & $\mathrm{I} / \mathrm{T}$ & $\mathrm{T}$ & I & I \\
\hline
\end{tabular}

${ }^{1}$ número de animais do rebanho; ${ }^{2}$ tipo de ordenha: mecânica (Me) ou manual (Ma); ${ }^{3}$ Plataforma de ordenha: madeira (M), azulejada (A), com canzil (C), separado do galpão (Sg); ${ }^{4}$ Arraçoamento: presente (C), ausente (S); ${ }^{5}$ resfriamento: imersão de latões (I), tanque de resfriamento (T).

mais de 50\% das atividades diárias de trabalho. A implementação da ordenha mecânica, verificada em cinco propriedades, propicia maior número de animais ordenhados por hora, independentemente da velocidade de ordenha e da produção individual de leite, melhorando a efetividade da mão-de-obra (LE DU, 1987).

A propriedade 6 possuía plataforma de ordenha construída em alvenaria e paredes azulejadas, facilitando sua higienização. Além disso, nas propriedades 6 e 7, encontraram-se plataformas isoladas das demais instalações, o que, segundo MACKENZIE (1980), é característica indispensável para que se produza leite caprino com qualidade higiênica melhor.

Nas amostras do leite analisadas, foram identificados coliformes totais em sete das propriedades estudadas (Tabela 2), sendo que as contagens variaram entre zero e 1,4 x $10^{6} \mathrm{UFC} \mathrm{mL}^{-1}$. Cinco propriedades (2, 4, 5, 6 e 8) apresentaram coliformes totais nas duas coletas. Em duas propriedades (1 e 3), na segunda coleta, e, em uma propriedade (7), nas duas coletas, não foram encontrados coliformes totais. Coliformes fecais foram encontrados nas propriedades 2 e 8 (3,4 x $10^{4} \mathrm{UFC} \mathrm{mL}^{-1} \mathrm{e}$ $4,1 \times 10^{4} \mathrm{UFC} \mathrm{mL}^{-1}$, respectivamente), na segunda coleta. Embora o critério microbiológico estabelecido para o leite de cabra cru seja a contagem padrão em placa(máximo de $5 \times 10^{5} \mathrm{UFC} / \mathrm{mL}$ ), os coliformes totais e termotolerantes são utilizados como critério microbiológico para leite pasteurizado (2 e 0UFC $\mathrm{mL}^{-1}$, respectivamente) e esterilizado (1 e 0UFC $\mathrm{mL}^{-1}$, respectivamente) (BRASIL, 2000).

Enquanto os coliformes totais são bons indicadores da qualidade higiênica de um modo geral, durante o processo de fabricação do alimento (REIBNITZ et al., 1998), os estafilococos tornaram-se importantes, devido à possibilidade de produção de toxinas no alimento, podendo levar à toxinfecção alimentar (WENDPAP \& ROSA, 1993).

No presente estudo, observou-se contagem de unidades formadoras de colônias típicas de estafilococos coagulase-positiva inferior às atípicas. As contagens de colônias típicas variaram entre 0 e $4 \mathrm{x}$ $10^{3} \mathrm{UFC} \mathrm{mL}^{-1}$. Nenhuma colônia, típica ou atípica, foi confirmada como estafilococos coagulase-positiva. Esse resultado pode estar relacionado com o fato de serem os estafilococos coagulase-negativa (SCN) os agentes mais encontrados na glândula mamária dos caprinos (CONTRERAS et al., 1997; MURICY et al., 2002; SANTOS et al., 2004).

Em pesquisa anterior, no leite cru amostrado na plataforma de recepção de um laticínio, encontraramse $8,4 \times 10^{4} \mathrm{UFC} \mathrm{mL}^{-1}$ como média de estafilococos coagulase-positiva presentes em todas as amostras analisadas (PICOLI et al., 2006). Na Itália, foi verificada média de $1,2 \times 10^{4} \mathrm{UFC} \mathrm{mL}^{-1}$ de $\boldsymbol{S}$. aureus, em $43 \%$ das amostras de leite de mistura analisadas (FOSCHINO et al., 2002), e, na Suíça, este microrganismo foi observado em 31,7\% das amostras analisadas (MUEHLHERR et al., 2003).

Por outro lado, ABO-ELNAGA et al. (1985) não encontraram $S$. aureus em amostras individuais de leite e FOSCHINO et al. (2002) verificaram que 90\% das amostras de leite de mistura analisadas continham SCN. Embora apenas contagens elevadas de $\boldsymbol{S}$. aureus $\left(10^{5} \mathrm{UFC}^{-1}\right)$ sejam consideradas como risco da presença de enterotoxina nos alimentos, os SCN também têm sido apontados como potencialmente enterotoxigênicos (BAUTISTA et al., 1988), podendo vir a ter algum significado para a segurança dos 
Tabela 2 - Contagem de coliformes totais, coliformes fecais e estafilococos coagulase-negativa (UFC mL $L^{-1}$ ) em amostras de leite de mistura caprino coletadas em duas visitas realizadas a oito propriedades no Rio Grande do Sul.

\begin{tabular}{|c|c|c|c|c|c|c|}
\hline \multirow[t]{2}{*}{ Propriedades } & \multicolumn{2}{|c|}{ coliformes totais } & \multicolumn{2}{|c|}{ coliformes fecais } & \multicolumn{2}{|c|}{ estafilococos } \\
\hline & visita 1 & visita 2 & visita 1 & visita 2 & visita 1 & visita 2 \\
\hline 1 & $5,2 \times 10^{3}$ & 0 & 0 & 0 & $2 \times 10^{3}$ & 0 \\
\hline 2 & $1,3 \times 10^{5}$ & $4,3 \times 10^{3}$ & 0 & $3,4 \times 10^{3}$ & $1 \times 10^{3}$ & 0 \\
\hline 3 & $1,2 \times 10^{4}$ & 0 & 0 & 0 & $6 \times 10^{3}$ & 0 \\
\hline 4 & $1,2 \times 10^{5}$ & $9 \times 10^{3}$ & 0 & 0 & $3 \times 10^{3}$ & $1 \times 10^{3}$ \\
\hline 5 & $1,4 \times 10^{4}$ & $9 \times 10^{3}$ & 0 & 0 & 0 & $1 \times 10^{3}$ \\
\hline 6 & $1,4 \times 10^{6}$ & $8 \times 10^{4}$ & 0 & 0 & $8 \times 10^{2}$ & $1,3 \times 10^{3}$ \\
\hline 7 & 0 & 0 & 0 & 0 & 0 & $4 \times 10^{2}$ \\
\hline 8 & $1,3 \times 10^{5}$ & $6,8 \times 10^{3}$ & 0 & $4,1 \times 10^{3}$ & $3 \times 10^{2}$ & $4 \times 10^{3}$ \\
\hline
\end{tabular}

alimentos. Comparando-se os valores de coliformes totais e fecais e estafilococos observados entre as propriedades que utilizam ordenha mecânica e aquelas que empregam a ordenha manual, não houve diferença estatística significativa $(\mathrm{P}>0,05)$. Ao contrário, DELGADO-PERTIÑEZ et al. (2003) e ZWEIFEL et al. (2005), ao avaliarem a qualidade de leite caprino pela quantificação de mesófilos totais, observaram número significativamente menor de microrganismos em leite obtido por ordenha manual, em comparação ao obtido por ordenha mecânica.

O leite caprino naturalmente tem baixo conteúdo bacteriano na saída do teto, sendo que o úbere e as instalações tendem a apresentar sujidades, que poderão comprometer sua qualidade (MACKENZIE, 1980). Dessa forma, a refrigeração é importante na manutenção das condições bacteriológicas do leite até seu beneficiamento. Recémordenhado, deve ser refrigerado a $2-3^{\circ} \mathrm{C}$ quando a coleta é feita em dias alternados, visando-se a, reduzir o crescimento de microrganismos psicotrófilos decorrentes do manuseio inadequado (LANGE \& BRITO, 2003). Um leite com baixo número de microrganismos pode ser conservado a $4^{\circ} \mathrm{C}$ durante três dias, sem alteração de sua qualidade. Entretanto, a partir do terceiro dia, é atingido o limiar crítico à alteração das características microbiológicas do produto (MAHIEU, 1985). O fato de o leite ser recolhido semanalmente nessas propriedades, sendo mantido, desta forma, estocado sob refrigeração por um período prolongado, pode ter contribuído à baixa qualidade do leite de mistura no que diz respeito à contagem total de bactérias.

Dessa forma, a presença de coliformes no leite de rebanho poderia estar relacionada aos procedimentos de ordenha deficientes, bem como ao armazenamento do leite em latões em imersão, verificado em seis propriedades. Esse tipo de resfriador dificilmente irá manter o leite nas condições ideais (DÜRR, 1999). Isso porque a conservação do leite acima de $4^{\circ} \mathrm{C}$ permite a multiplicação de microrganismos psicrófilos, os quais poderiam influenciar na qualidade do leite devido à produção de enzimas lipolíticas e proteolíticas, que são termoestáveis (MAHIEU, 1985). As bactérias psicrofilas presentes no leite após a pasteurização são provavelmente bactérias termotolerantes comuns no leite, que poderiam afetar o produto se o tempo de refrigeração e prateleira fosse superior aos estabelecidos pela legislação, ou se fossem utilizados na fabricação de outros produtos ou derivados com tempo de prateleira ou maturação prolongado (MORAES et al., 2005). Por outro lado, o resfriamento em tanques de expansão, presente em três propriedades, é o ideal para o resfriamento e a conservação do leite (DÜRR, 1999). Nesse sistema, o calor do leite, sob constate agitação, é transferido para o meio de resfriamento através da parede de aço inoxidável. Esse processo permite a rápida redução da temperatura do leite após a ordenha, uma das estratégias mais eficazes para garantir a qualidade microbiológica do produto (CAVALCANTI, 2006). Entretanto, o uso do tanque de expansão nessas propriedades não influenciou na qualidade do leite, uma vez que o uso desse sistema de refrigeração apenas mantém a qualidade do leite ordenhado, não sendo observada diferença significativa $(P>0,05)$ de coliformes totais e fecais e Staphylococcus sp. entre as propriedades que utilizam refrigeração em latões em imersão e aquelas que utilizam tanque de expansão. Resultado semelhante foi observado por ZWEIFEL et al. (2005), na Suíça.

Na Itália, a média de coliformes totais verificada em amostras de leite do rebanho foi de $9,1 \times 10^{3} \mathrm{UFC} \mathrm{mL}^{-1}$, tendo sido verificada diferença 
significativa no número de coliformes entre propriedades (FOSCHINO et al., 2002), o que pode estar relacionado a diferenças de instalações e manejo.

Por outro lado, amostras de leite armazenadas em latões imersos em água refrigerada por até três dias apresentaram contagem máxima de $1 \times 10^{2}$ UFC $\mathrm{mL}^{-1}$ de coliformes fecais (MURICY et al., 2002) no RS e na Suíça, sendo que $61,6 \%$ das amostras coletadas em tanques de expansão apresentaram enterobactérias (MUEHLHERR et al., 2003).

Pesquisas realizadas sobre a microbiota do leite e seus derivados mostram que esta apresenta uma grande diversificação, relacionada com as condições higiênicosanitárias da ordenha, a conservação do leite, o tipo de processamento, o tempo e a temperatura do armazenamento, a qualidade microbiológica da água, dentre outros fatores (TZANETAKIS \& TZANETAKIS, 1992).

Nas amostras de água coletadas, foram encontrados coliformes totais em 87,5\% (coletas 1 e 2) das propriedades, de modo que os valores de NMP variaram de zero a 2.400UFC $100 \mathrm{~mL}^{-1}$ (Tabela 3). Foram encontrados coliformes fecais em $5(62,5 \%)$ e $4(50 \%)$ das propriedades (coletas 1 e 2, respectivamente), sendo que os valores de NMP variaram de zero a 79 UFC $100 \mathrm{~mL}^{-1}$ (Tabela 3). Esses valores de coliformes estavam de acordo com os parâmetros $\left(10^{3} \mathrm{~mL}^{-1}\right)$ aceitos pelo Conselho Nacional do Meio Ambiente - para águas de Classe 2 (BRASIL, 1986). Mesmo estando de acordo com os parâmetros, a água pode ter contribuído com a presença de coliformes totais e fecais no leite de mistura, uma vez que a higiene dos tetos e equipamentos era feita sem que houvesse um tratamento prévio. A introdução de coliformes em uma planta de fabricação de derivado de leite de cabra pela água foi anteriormente demonstrada (PICOLI et al., 2006).
Entretanto, no presente estudo, provavelmente outros mecanismos de contaminação por coliformes estiveram presentes, uma vez que, nas propriedades 2 e 4, esses microorganismos foram encontrados no leite de mistura, embora não tenha sido verificada sua presença na água. Por outro lado, na propriedade 8, observou-se o inverso, havendo a presença de coliformes na água, mas não no leite de mistura. Determinou-se diferença significativa $(\mathrm{P}=0,0109)$ entre as contagens medianas de coliformes totais na água $\left(3,2 \times 10^{1}\right)$ e no leite $\left(9 \times 10^{3}\right)$. Entretanto, não houve associação significativa entre as presenças de coliformes na água e no leite $(\mathrm{P}=0,45)$.

Fatores como o número de animais no rebanho (ZWEIFEL et al., 2005) e as práticas de higienização utilizadas (DELGADO-PERTIÑEZ et al., 2003) podem ter influenciado na presença de fezes nos tetos e nas condições higiênicas da plataforma de ordenha, contribuindo à presença de microrganismos no leite. Entretanto, essas variáveis não foram avaliadas no presente estudo.

A partir disso, observou-se que, apesar de haver orientação técnica única em todas as propriedades, houve variação tanto nos aspectos de manejo dos animais na ordenha como na higiene, obtenção e armazenagem do leite, refletindo-se na qualidade higiênica do leite de mistura.

\section{CONCLUSÕES}

Em todas as propriedades amostradas, verificou-se presença de coliformes em, pelo menos, uma amostra de leite ou de água. Entretanto, não foi

Tabela 3 - Coliformes totais e fecais em amostras de água coletadas em oito propriedades produtoras de leite caprino, Rio Grande do Sul.

\begin{tabular}{|c|c|c|c|c|}
\hline \multirow{3}{*}{ Propriedades } & \multicolumn{2}{|c|}{ Coliformes totais } & \multicolumn{2}{|c|}{ Coliformes fecais } \\
\hline & \multicolumn{2}{|c|}{$\left(\mathrm{UFC} 100 \mathrm{~mL}^{-1}\right)$} & \multicolumn{2}{|c|}{$\left(\mathrm{UFC} 100 \mathrm{~mL}^{-1}\right)$} \\
\hline & Visita 1 & Visita 2 & Visita 1 & Visita 2 \\
\hline 1 & 280 & 33 & 0 & 4,5 \\
\hline 2 & 920 & 0 & 0 & 0 \\
\hline 3 & 2.400 & 81 & 70 & 69 \\
\hline 4 & 4,5 & 2 & 0 & 0 \\
\hline 5 & 7,8 & 79 & 7,8 & 79 \\
\hline 6 & 31 & 140 & 2 & 0 \\
\hline 7 & 0 & 33 & 0 & 33 \\
\hline 8 & 2 & 7 & 2 & 2 \\
\hline
\end{tabular}

Ciência Rural, v.38, n.3, mai-jun, 2008. 
evidenciada associação significativa entre as condições de ordenha e o sistema de armazenamento sob refrigeração empregados nestas propriedades e a presença de coliformes no leite.

\section{REFERÊNCIAS}

ABO-ELNAGA, I.G. et al. Bacteria and food poisoning organisms in milk. Nahrung, Berlim, v.29, n.4, p.375-380, 1985.

BAUTISTA, L. et al. A quantitative study of enterotoxin production by sheep milk Staphylococci. Applied and Environmental Microbiology, Washington, v.54, p.566-569, 1988.

BRASIL. Conselho Nacional de Meio Ambiente. Resolução CONAMA n. 20, de 18 de junho de 1986. Diário Oficial da União, Brasília, DF, 30 jul. 1986. Capturado em 12 mar. 2003. Online. Disponível na Internet: http://www.mma.gov.br.

BRASIL. Ministério da Agricultura, Pecuária e Abastecimento. Instrução Normativa n. 37 de 31 de outubro de 2000. Capturado em 11 set. 2006. Online. Disponível na Internet: http:// agricultura.gov.br.

CARDOSO, W.M. et al. Contagem de microrganismos. In: CARDOSO, W.M. Análise microbiológica de alimentos. Rio de Janeiro: Merk, 1985. p.20-27.

CAVALCANTI, E.R.C. Fatores que interferem na qualidade do leite. Capturado em 11 set.2006. Online. Disponível na Internet: http://www.cefeturutai.edu.br/documentos/artigo_ leite.doc

CONTRERAS, A. et al. Persistence of subclinical intramammary pathogens in goats throughout lactation. Journal of Dairy Science, v.80, n.11, p.2815-2819, 1997.

DELGADO-PERTIÑEZ, M. et al. Effect of hygiene-sanitary management on goat milk quality in semi-extensive systems in Spain. Small Ruminant Research, Amsterdam, v.47, p.5161, 2003.

DÜRR, J.W. Manual da qualidade do leite. Passo Fundo: SENAR-RS, 1999. 69p.

FOSCHINO, R. et al. Microbial composition including the incidence of pathogens of goat milk from bergamo region of Italy during lactation year. Journal of Dairy Research, Cambridge, v.69, n.2, p.213-225, 2002.

FRANSON, M.A.H. (Ed.). Standard methods for examination of water and wastewater. 19.ed. Washington: APHA, 1995. 1074p.

LANGE, C.C.; BRITO, J.R.F. Influência da qualidade do leite na manufatura e vida de prateleira dos produtos lácteos: papel das altas contagens microbianas. In: BRITO, J.R.F.; PORTUGAL, J.A.B. (Ed.). Diagnóstico da qualidade do leite, impacto para a indústria e a questão dos resíduos de antibióticos. Juiz de Fora: EMBRAPA-CNPGL, 2003. p.119-137.

LE DU, J.F. Facilities and equipment for hand and machine milking of goats, Brasília, 1987. In: INTERNATIONAL CONFERENCE ON GOATS, 4., 1987, Brasilia, DF. Anais... Brasília: Embrapa, 1987. p.269-281.
MACKENZIE, D. Goat husbandry. 4.ed. London: Faber \& Faber, 1980. 375p.

MAHIEU, E. Modificações do leite depois da recolha. In: LUQUET, F.M. O leite: do úbere à fábrica de laticínios. Sintra: Europa-América, 1985. v.1, p.233-284.

MARCONI, M.A.; LAKATUS, E.M. Técnicas de pesquisa. 3.ed. São Paulo: Atlas, 1996. 231p.

MORAES, C.R. et al. Qualidade microbiológica do leite cru produzido em cinco municípios do Estado do Rio Grande do Sul, Brasil. Acta Scientiae Veterinariae, Porto Alegre, v.33, p.259-264, 2005.

MUEHLHERR, J.E. et al. Microbiological quality of raw goat's and ewe's bulk-tank milk in Switzerland. Journal of Dairy Science, Savoy, v.86, n.12, p.3849-3856, 2003.

MURICY, R.F. et al. Pontos de contaminação de leite produzido em uma propriedade de caprinos no município de Viamão, Rio Grande do Sul, Brasil. Revista da Faculdade de Zootecnia, Veterinária e Agronomia, Uruguaiana, v.9, n.1, p.42-47, 2002.

PAGANO, M.; GAUVREAU, K. Princípios de bioestatística. 2.ed. São Paulo: Thompson, 2000. 506p.

PICOLI, S.U. et al. Quantificação de coliformes, Staphylococcus aureus e mesófilos presentes em diferentes etapas da produção de queijo frescal de leite de cabra em laticínio. Ciência e Tecnologia de Alimentos, Campinas, v.26, n.1, p.65-69, 2006.

PRATA, L.F. et al. Composição, perfil nitrogenado e características do leite caprino (Saanen). Região Sudeste, Brasil. Ciência e Tecnologia de Alimentos, Campinas, v.18, n.4, p.428-432, 1998.

REIBNITZ, M.G.R. et al. Presencia de coliformes fecales, Escherichia coli y Staphylococcus aureus coagulasa y DNAasa positivos en queso “colonial” comercializado en el Município de Blumenau, Estado de Santa Catarina, Brasil. Revista Argentina de Microbiologia, Buenos Aires, v.30, n.1, p.812, 1998.

SANTOS, A.R. et al. Validação da contagem de células somáticas e do califórnia mastitis test como método diagnóstico da mamite subclínica em caprinos. Revista de Ciências Agroveterinárias, Lages, v.3, n.1, p.50-55, 2004.

SILVA, N. et al. Manual de métodos de análise microbiológica de alimentos. São Paulo: Varella, 1997. 295p.

THIOLlent, M. Metodologia da pesquisa-ação. 5.ed. São Paulo: Cortez, 1992. 107p.

TZANETAKIS, E.L.; TZANETAKIS, N. Microbiological of white bined cheese made from raw goat milk. Food Microbiology, Amsterdan, v.9, p.13-19, 1992.

WENDPAP, L.L.; ROSA, O.O. Presença de Staphylococcus aureus em queijo Minas consumido no município de Cuiabá MT. Higiene Alimentar, São Paulo, v.7, n.27, p.23-29, 1993.

ZWEIFEL, C. et al. Influence of different factors in milk production on standard plate count of raw small ruminant's bulk-tank milk in Switzerland. Small Ruminant Research, Amsterdam, v.58, p.63-70, 2005. 